\title{
Planejamento para o e-commerce em pequenas e médias empresas: uma abordagem via Dinâmica de Sistemas
}

\author{
Leila Keiko Canegusuco Jansen (POLIUSP) leila.jansen@poli.usp.br \\ Fernando José Barbin Laurindo (POLIUSP) fjblau@usp.br
}

\begin{abstract}
Resumo
Com a globalização da economia um dos fenômenos tecnológicos que despontou, apoiado pela Internet, foi o comércio eletrônico - e-commerce. Essa nova maneira de comercializar também foi adotada pelas pequenas e médias empresas, que ai encontraram uma poderosa ferramenta para aumentar seu faturamento, mas que esconde algumas armadilhas. Este artigo apresenta um estudo de caso realizado em uma pequena empresa nacional, representante de matérias primas da cadeia de suprimentos do setor químico, estabelecida há 30 anos no mercado. Esta empresa decidiu experimentar o e-commerce como um novo canal de distribuição de um produto inovador para o mercado doméstico/institucional. Os fatores críticos de sucesso para o e-commerce em pequenas empresas foram considerados, bem como o relacionamento dinâmico existente entre eles. Do estudo ficou evidenciada a importância de considerar essa decisão de aderir ao e-commerce de modo alinhado à estratégia competitiva do negócio e apoiado em adequado planejamento para a implantação. Abordou-se o problema segundo o enfoque da Dinâmica de Sistemas.
\end{abstract}

Palavras chave: e-Commerce, Pequenas e Médias Empresas, Dinâmica de Sistemas.

\section{Introdução}

As pequenas e médias empresas possuem uma participação importante na economia atual. Essa importância é explicada por vários motivos como o número de empresas, a contribuição que fazem ao produto bruto nacional, geração de emprego e prosperidade econômica local (BIANCHI, 2002).

No Brasil os números relativos aos pequenos negócios impressionam. Dados do IBGE (Disponível em: <www.sebrae.com.br>. Acesso em: 5.abr.2005) mostram que em 2002 o número de micro e pequenas empresas no setor formal urbano (excluindo o setor governamental) era de 4,88 milhões, ou seja, 99,2\% do total de 4,918 milhões de empresas. Essas empresas empregaram $56,1 \%$ da força de trabalho formal no setor urbano.

Assim como as grandes empresas, as pequenas e médias também vêm buscando maneiras de aumentar seus ganhos de produtividade e reduzir custos para se manterem competitivas no mercado. Se de um lado comparativamente às grandes elas carecem de alguns recursos críticos como recursos humanos, suporte de ferramentas e informação gerenciais, de outro lado elas possuem mais flexibilidade associada a alto potencial criativo dos empreendedores (BIANCHI, 2002). Mesmo assim, tem sido enfatizado que as pequenas e médias empresas defrontam-se com dificuldades estruturais para sobreviverem nos primeiros estágios de seu ciclo de vida, por vezes não alcançando o segundo ano (BIANCHI, 2003).

Com a globalização da economia um dos fenômenos tecnológicos que despontou, apoiado pela Internet, foi o comércio eletrônico - e-commerce. Essa nova maneira de comercializar também foi adotada pelas pequenas e médias empresas, que aí encontraram uma poderosa ferramenta para aumentar seu faturamento, mas que esconde algumas armadilhas. 
Este artigo apresentará um estudo de caso realizado em uma pequena empresa nacional denominada de Alfa, representante de matérias primas da cadeia de suprimentos do setor químico, estabelecida há 30 anos no mercado. Esta empresa decidiu experimentar o ecommerce como um novo canal de distribuição de um produto inovador no mercado. Do estudo ficou evidenciada a importância de considerar essa decisão sob um ponto de vista de estratégia competitiva do negócio, apoiado em adequado planejamento para a implantação. Abordou-se o problema segundo o enfoque da Dinâmica de Sistemas. O trabalho foi desenvolvido seguindo os seguintes passos: a) Definição do problema; b) Identificação dos Fatores Críticos de Sucesso do negócio; c) Elaboração do Diagrama de Fluxo e Estoque; d) Conclusões.

\section{Conceitos básicos}

\subsection{Internet e e-commerce em pequenas e médias empresas}

A Internet penetrou lares e negócios em alta velocidade; o e-mail e a World Wide Web provaram ser fenômenos tecnológicos de sucesso (DREW, 2003). Mas, segundo Porter (2001) apesar de a Internet ser uma nova tecnologia extremamente importante que recebeu muita atenção de empreendedores, executivos, investidores e observadores de negócio, ela não modifica tudo, nem torna obsoletas todas as antigas regras sobre empresas e competição. Deve-se mudar a idéia da retórica sobre internet industries, e-business strategies e new economy e ver a Internet pelo que ela é, ou seja, um poderoso conjunto de ferramentas que pode ser usado, de modo inteligente ou não, em quase todas as indústrias e como parte de quase qualquer estratégia.

Poucas empresas puramente digitais sobreviveram ao colapso do início dos anos 2000. Mas algumas empresas já estabelecidas cujo modelo de negócio era uma mistura de bricks-andclicks se beneficiaram da experimentação e aprendizado dos novos entrantes e da maturidade das tecnologias suportadas na Internet (DREW, 2003).

Esses impactos causados pela Internet, conforme observaram Souitaris \& Cohen (2003) foram largamente citados na imprensa de negócios, mas até o momento não existem muitos estudos sistemáticos e em larga escala sobre o assunto nas publicações acadêmicas. Segundo esses autores a literatura acadêmica existente sobre a comercialização via Internet recai em duas categorias: surveys descritivos medindo o grau de adoção do e-commerce por empresas já estabelecidas e trabalhos exploratórios sobre estratégias de comercialização especificamente baseadas na Internet. Na primeira categoria, os primeiros resultados sobre a adoção do $e$ commerce mostravam que poucas empresas usavam ativamente a Internet por volta de 1997. Pesquisas mais recentes já mostraram um aumento na taxa de adoção.

Alguns estudos mais específicos investigaram as barreiras de adoção da internet em pequenas empresas na Holanda (WALCZUCH et al, 2000) e concluíram que a maior barreira era a preocupação de que a Internet ou o website não levassem a maior eficiência ou baixos custos.

Um estudo denominado projeto KITE- Knowledge and Information Transfer on Eletronic Commerce (CHAPPELL et al., 1999) foi realizado na Europa e teve como objetivo recomendar melhores práticas para auxiliar pequenas e médias empresas na condução com sucesso do e-commerce. O trabalho abrangeu 17 países e cobriu 600 atividades de ecommerce.

Mais recentemente, estudos na Inglaterra mostraram que as pequenas e médias empresas estão emergindo como significantes usuárias da Internet e do mesmo modo que as grandes empresas, estão adotando o e-commerce (DREW, 2003). Essas empresas estão colocando o $e$ commerce no centro de sua tecnologia e estratégia corporativa e planejam usar a Internet como meio de alcançar mudança transformacional. 


\subsubsection{Fatores críticos de sucesso do e-commerce em pequenas e médias empresas}

Segundo a definição de Rockart (1979) fatores críticos de sucesso representam um conjunto de determinadas áreas que se apresentarem resultados satisfatórios assegurarão um desempenho competitivo de sucesso para a organização.

Entre as conclusões do trabalho de Chappell \& Feindt (1999) consta que os fatores críticos de sucesso das pequenas e médias empresas que praticam o e-commerce não difere significativamente daqueles para as grandes organizações no mesmo ramo de negócios, embora as pequenas e médias empresas tenham maior dificuldade em alcançá-los devido as características próprias como menos recursos e organização. Os 11 fatores críticos de sucesso mais relevantes citados neste relatório estão apresentados no Quadro 1.

\begin{tabular}{|c|c|}
\hline Fator crítico de sucesso & Definição \\
\hline 1. Conteúdo & $\begin{array}{l}\text { Apresentação de um produto/serviço único ou inovador pela Internet, } \\
\text { de grande atratividade e apelo de compra. }\end{array}$ \\
\hline 2. Conveniência & Utilização do site para os propósitos para os quais ele foi projetado. \\
\hline 3. Controle & $\begin{array}{l}\text { A extensão na qual o negócio é capaz de monitorar significantes } \\
\text { processos relacionados ao e-commerce. Ex.: entregas, perguntas dos } \\
\text { clientes, atualização das informações, etc. }\end{array}$ \\
\hline 4. Interação & $\begin{array}{l}\text { A atitude da empresa em construir relacionamentos antes e depois } \\
\text { da venda. }\end{array}$ \\
\hline 5. Comunidade & $\begin{array}{l}\text { A habilidade de atrair e manter um grupo de clientes/parceiros de } \\
\text { interesses comuns trocando informações e serviços (ex.: através das } \\
\text { bases de dados). }\end{array}$ \\
\hline 6. Sensibilidade de Preço & $\begin{array}{l}\text { A sensibilidade de apresentar um produto/serviço a um preço } \\
\text { competitivo na Internet. }\end{array}$ \\
\hline 7. Imagem da Marca & A habilidade de construir uma marca. \\
\hline 8. Compromisso & Forte motivação em usar a Internet como alavanca para inovar. \\
\hline 9.Parceria & $\begin{array}{l}\text { A extensão na qual o negócio usa parceiros para alavancar a presença } \\
\text { na Internet e expandir os negócios. }\end{array}$ \\
\hline 10. Melhoria do Processo & A extensão na qual a empresa pode mudar e automatizar os processos. \\
\hline 11. Integração & $\begin{array}{l}\text { A provisão de links com sistemas de TI para suportar parceiros ou } \\
\text { melhorias de processos. }\end{array}$ \\
\hline
\end{tabular}

Quadro 1 - Fatores críticos de sucesso relevantes para o desempenho competitivo de pequenas e médias empresas que adotam o e-commerce

Fonte: Adaptado de Chappell et.al. (1999).

Um fundamental fator de sucesso "horizontal" que suporta todos os outros é o uso da tecnologia pelas pequenas e médias empresas (CHAPPELL \& FEINDT, 1999).

\subsection{Dinâmica de Sistemas}

Muitos e-business perseguiram a estratégia "get big fast", praticando preços baixos e utilizando fortemente o marketing para construir sua base de clientes, acreditando que haveria significativas fontes de retornos crescentes que favoreciam os grandes players e os primeiros a entrar. Até 2000 o mercado de capitais recompensou esta estratégia "get big fast", mas a partir de então os valores de mercado colapsaram e muitas empresas da nova economia faliram. O crescimento e queda das dot coms não é meramente um caso de bolha especulativa; muitas empresas tropeçam quando crescem tão rapidamente que se tornam incapazes de atender pedidos ou entregar serviços de qualidade (OLIVA et al., 2003).

A Dinâmica de Sistemas é uma ferramenta que estuda comportamentos dinâmicos como este. Pela Dinâmica de Sistemas, o comportamento "get big fast" é gerado por feedbacks positivos que criam retornos crescentes favorecendo as empresas agressivas; mas em alguns casos este crescimento é limitado por feedbacks negativos, como por exemplo recursos financeiros, qualidade de atendimento, etc. 
Alguns exemplos de sucesso da estratégia "get big fast" são a vitória do VHS (padrão de vídeo) sobre o Betamax; a Microsoft e Intel como padrão de PC's; no e-commerce, a Amazon.com. Mas, a maioria das empresas de e-commerce que procuraram seguir a estratégia "get big fast" faliram (OLIVA et al., 2003).

Visto que existam tantos casos de fracasso no comércio eletrônico, é fundamental para as empresas, mais ainda para as de pequeno e médio portes, que conheçam a fundo as características de comportamento dinâmico do seu negócio - os processos de acúmulo e esgotamento de seus recursos estratégicos, os efeitos de decisões tomadas no passado, etc para planejarem suas estratégias de modo cuidadoso.

\subsubsection{Estrutura e comportamento de Sistemas Dinâmicos}

O comportamento de um sistema surge de sua estrutura; esta estrutura consiste de malhas de feedback, estoques, fluxos, e não linearidades criadas pela interação da estrutura física e institucional do sistema com os processos de decisão do agentes que atuam sobre ele (STERMAN, 2000). O Quadro 2 apresenta alguns modos fundamentais de comportamento e a estrutura de feedback que os gera.

\begin{tabular}{|ll|}
\hline Modos fundamentais de comportamento & Estrutura que gera o comportamento \\
\hline crescimento exponencial & feedback positivo \\
$\begin{array}{l}\text { goal seeking } \\
\text { oscilação }\end{array}$ & $\left.\begin{array}{l}\text { feedback negativo } \\
\text { feedback negativo com atraso de tempo } \\
\begin{array}{l}\text { crescimento em S } \\
\text { crescimento e } \text { overshoot } \\
\text { overshoot e colapso }\end{array}\end{array}\right\} \begin{array}{l}\text { interações não lineares de estruturas de feedbacks } \\
\text { fundamentais }\end{array}$ \\
\hline
\end{tabular}

Quadro 2 - Modos fundamentais de comportamento e as estruturas que os geram

Fonte: Adaptado de Sterman (2000)

Embora existam apenas dois tipos de malhas de feedback (positiva e negativa) os sistemas complexos podem facilmente conter milhares de malhas de ambos os tipos, acoplados uns aos outros, com muitos atrasos de tempo, não-linearidades, e estoques. As malhas positivas tendem a reforçar ou amplificar o que quer que esteja acontecendo no sistema. Elas são autocatalíticas. As malhas negativas agem contrariamente e se opõem à mudança. Elas descrevem processos que tendem a ser auto-limitadores, que criam balanço e equilíbrio.

A Figura 1 apresenta os comportamentos que serão citados no desenvolvimento deste artigo, o crescimento exponencial e o overshoot e colapso.

\section{Estudo de caso da empresa Alfa}

A empresa Alfa está estabelecida no mercado há 30 anos. Tradicionalmente ela representa grandes empresas do exterior e abastece o setor químico com matérias primas. Nesta atividade a empresa Alfa possui uma base estável de aproximadamente 300 clientes.

No final de 2004, em busca de diversificação ela passou a ser a representante única no Brasil de um produto inovador que não se enquadra no seu portfólio habitual de produtos. Trata-se de um produto de consumo doméstico/institucional.

No estabelecimento da estratégia comercial para este novo produto, a empresa Alfa tem a intenção de experimentar o comércio eletrônico através da Internet. A proposta é de vender apenas este novo produto eletronicamente. E antes do lançamento, a empresa resolveu testar o mercado apresentando o produto em uma feira setorial. O stand da empresa Alfa foi o mais visitado na feira, sendo a aceitação do produto surpreendente. Passado o evento a quantidade de e-mails de potenciais clientes interessados em conhecer o produto e outros tantos já querendo fechar pedidos apresentou um crescimento exponencial, impactando a realização das atividades habituais da empresa. 


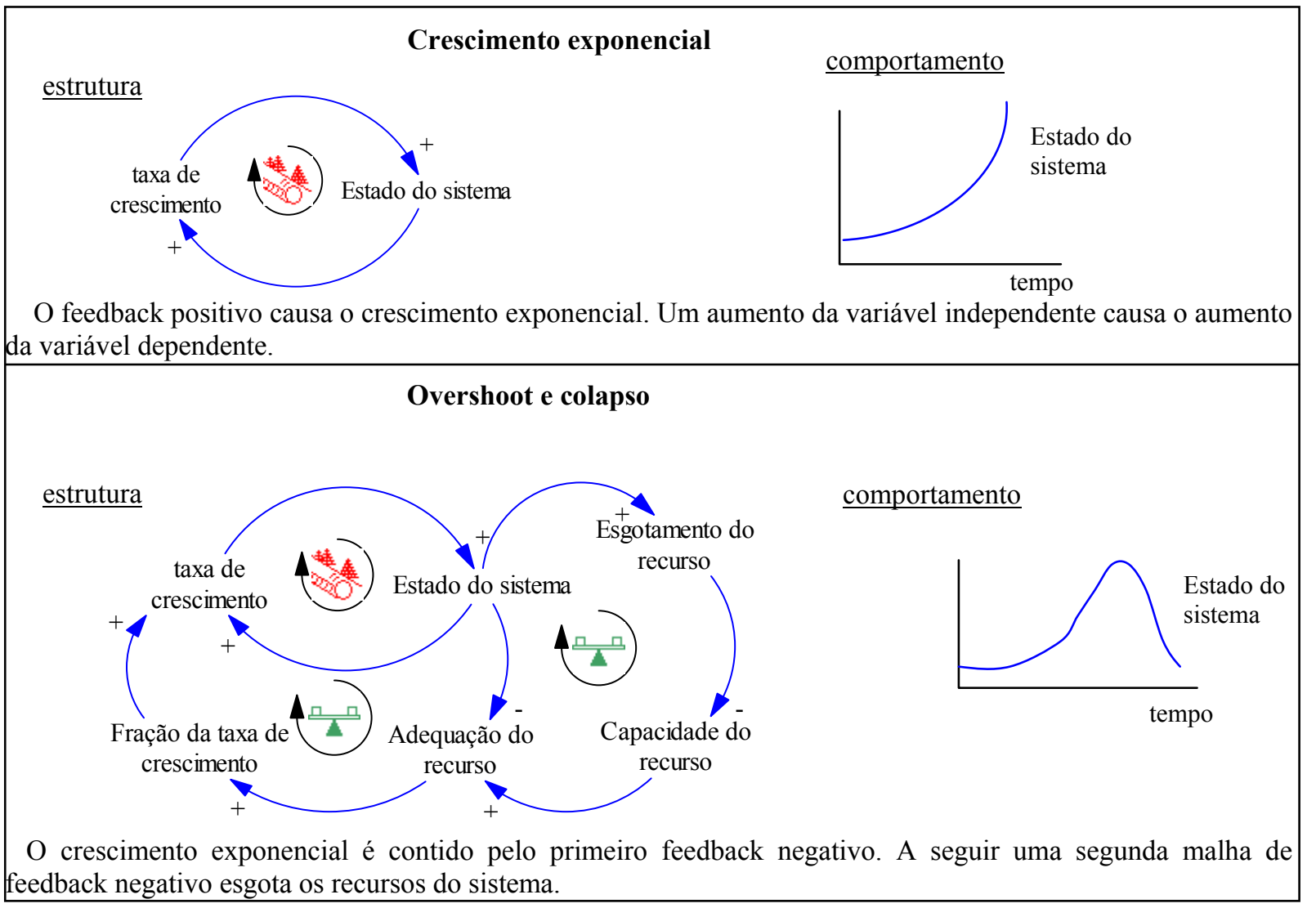

Figura 1 - Estrutura e comportamento de alguns sistemas

Fonte: Adaptado de Sterman (2000)

Bastante surpreso com este comportamento do mercado, que superou as previsões de demanda em até 100 vezes mais, o proprietário resolveu analisar mais a fundo a questão. Foilhe então sugerido este trabalho, baseado na Dinâmica de Sistemas.

A justificativa de ser proposta a Dinâmica de Sistemas pode ser dada pelas palavras de Sterman (2001): "Apesar de o mundo ser dinâmico, estar em constante evolução e interconectado tomamos decisões usando modelos mentais que são estáticos, limitados e reducionistas. A heurística que usamos para julgar relacionamentos causais leva a mapas cognitivos que ignoram feedbacks, atrasos no tempo, e outros elementos da complexidade dinâmica. Para melhorar a habilidade de aprender a respeito e gerenciar sistemas complexos as ferramentas precisam ser capazes de capturar essas fontes de complexidade dinâmica."

\section{Metodologia}

O trabalho realizado baseou-se em entrevistas com o proprietário e gerência da empresa Alfa. O tempo de duração foi de três meses. Os dados utilizados são primários, fornecidos pela própria empresa. A metodologia utilizada contou com os seguintes passos:

a) Definição do problema. Para a comercialização do novo produto que possui um mercado potencial muito grande, de consumo doméstico e institucional como hospitais, shoppings centers, escolas, etc., a Alfa pretende utilizar a Internet. Essa decisão foi tomada inicialmente baseada no tino que o proprietário possui para conduzir seus negócios. Mas, a empresa não detém o conhecimento das novas tecnologias baseadas na Internet. Não são conhecidos também impactos que essa tecnologia possa causar em uma pequena empresa. A questão colocada é a seguinte: Com tantos casos de empresas que falharam ao utilizarem a Internet para 
comercialização, como prever o que acontecerá com a Alfa?

b) Identificação dos Fatores Críticos de Sucesso do negócio. Nessa fase do trabalho foram levantados na literatura os fatores críticos de sucesso para pequenas e médias empresas que utilizam o e-commerce. A utilização dessa base teórica foi importante, pois para a obtenção de uma estratégia baseada em e-commerce a direção da Alfa necessitava de uma visão sistêmica dos fatores críticos de sucesso, de como cada um deles se relaciona com os outros dinamicamente.

c) Elaboração do Diagrama de Fluxo e Estoque. Nessa etapa foram elaborados diagramas de fluxo e estoque. Este tipo de representação fornece mais informações que o diagrama de enlace causal. Estoques (níveis ou estados) são fundamentais na geração do comportamento do sistema. Fluxos (taxas) causam as mudanças nos estoques. Esses diagramas identificaram as principais malhas de feedback que reforçam o crescimento da Alfa e as que podem limitá-lo.

d) Conclusões. Nesta etapa são consolidadas as conclusões do trabalho.

\section{Resultados obtidos}

- Fatores críticos de sucesso para o e-commerce da Alfa.

A Alfa embora pequena, contando com cerca de 25 funcionários, possui um corpo de direção muito bem capacitado: o proprietário é engenheiro de escola de primeira linha e tem ao seu lado na empresa a sua filha, que possui mestrado em economia no exterior. Mesmo assim, os fatores críticos de sucesso para esse novo empreendimento eram em parte desconhecidos e já na primeira análise alguns suscitaram questionamentos.

\begin{tabular}{|c|c|c|}
\hline Fator crítico de sucesso & Adequação da Alfa & Observações \\
\hline 1. Conteúdo & $\mathrm{OK}$ & O produto é inovador e de grande apelo de compra \\
\hline 2. Conveniência & não OK & $\begin{array}{l}\text { A empresa já tem site de apresentação para as } \\
\text { atividades tradicionais. Não foi pensado em site } \\
\text { específico para o e-commerce. }\end{array}$ \\
\hline 3. Controle & não OK & Site ainda não monitora entregas, por exemplo. \\
\hline 4. Interação & $\mathrm{OK}$ & A Alfa já tem desenvolvida esta habilidade via e-mail \\
\hline 5. Comunidade & --- & A Alfa ainda não pensou em desenvolver. \\
\hline 6. Sensibilidade de Preço & $\mathrm{OK}$ & A Alfa tem boa base para compor o preço adequado \\
\hline 7. Imagem da Marca & $\mathrm{OK}$ & A marca já está estabelecida. \\
\hline 8. Compromisso & não OK & A Internet é vista como outro canal \\
\hline 9. Parceria & --- & A Alfa ainda não pensou em desenvolver. \\
\hline 10. Melhoria do Processo & --- & A Alfa ainda não pensou em desenvolver. \\
\hline 11. Integração & --- & A Alfa ainda não pensou em desenvolver. \\
\hline
\end{tabular}

Quadro 3 - Situação da adequação dos fatores críticos de sucesso pela Alfa

\section{- Diagrama de Fluxo e Estoque}

O primeiro diagrama realizado foi o de Alfa com a utilização do website para a venda do novo produto. O modelo baseou-se em Bianchi \& Bivona (2002) e está apresentado na Figura 2.

Verifica-se que duas malhas de feedback positivo são capazes de gerar o crescimento exponencial. A base de cliente através da propaganda "boca a boca" influencia no crescimento da própria base com o primeiro feedback positivo. Com mais clientes há um aumento do faturamento, que por sua vez permite o investimento na ampliação do website, alimentando a base de clientes - este é o segundo feedback positivo. Mas a base de clientes gera mais solicitações no site: perguntas sobre utilização do novo produto, posição das entregas, etc.; que impacta no recurso de tempo do proprietário para a condução do seu 
negócio. Este é o feedback negativo que pode impedir o crescimento do negócio.

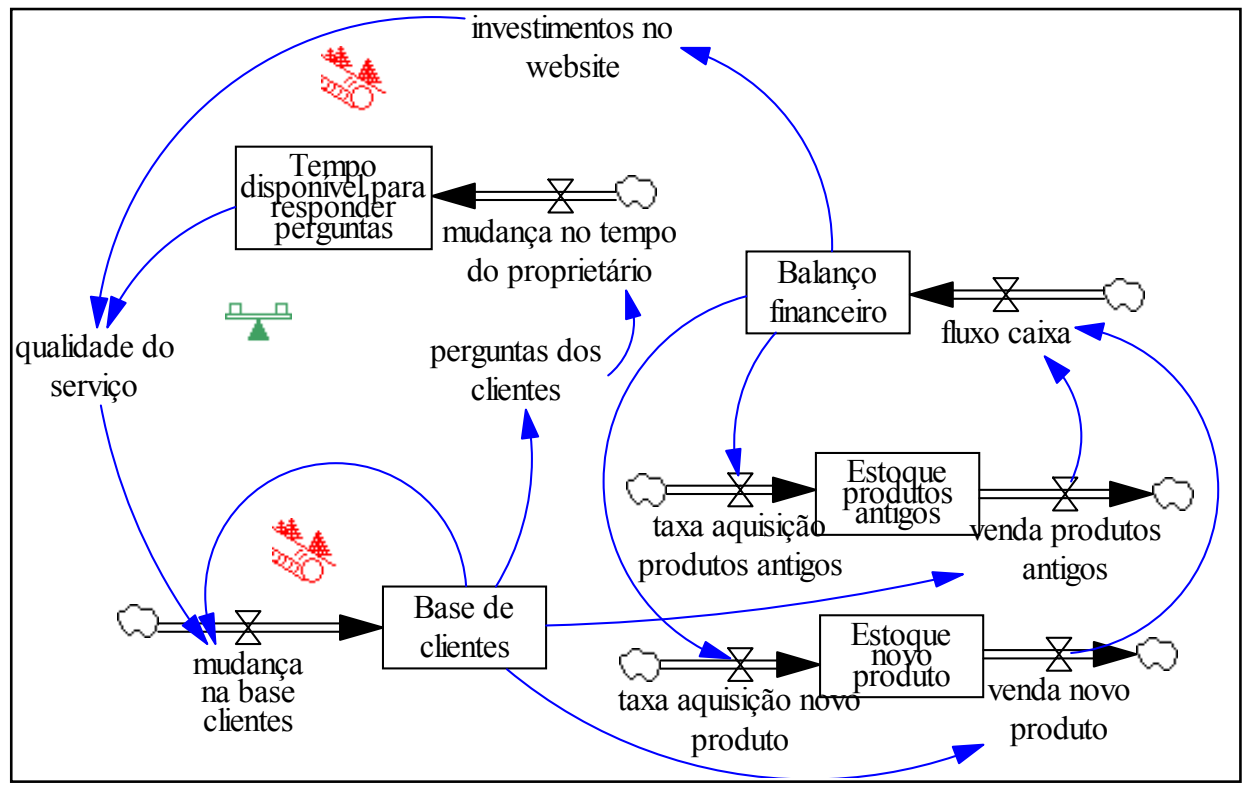

Figura 2 - Diagrama de fluxo e estoque considerando o e-commerce

- Relacionamento dinâmico dos fatores críticos de sucesso

O diagrama de fluxo e estoque permite uma outra leitura através dos fatores críticos de sucesso. Essa visão sistêmica da dinâmica que os fatores críticos de sucesso possuem entre si é importante, pois demonstra à direção de Alfa que mesmo que se busque a otimização de cada um deles em separado (veja que no Quadro 3 eles foram considerados OK) pode-se não chegar à otimização do todo. Ex.: Com um conteúdo (produto inovador) de forte apelo de compra espera-se um bom volume de vendas e aumento da base de clientes. Aumentando os clientes o proprietário diminuirá o tempo disponível que dispõe para a interação com os clientes (na pré e pós venda), causando uma queda na qualidade do serviço que no futuro poderá abalar a imagem da marca.

\section{Conclusões}

Com a estrutura atual da empresa Alfa é bastante provável que o empreendimento do $e$ commerce venha a falhar. O próprio proprietário ao chegar a este ponto da análise sentiu -se mais convencido a procurar utilizar um recurso que até então passava apenas de uma idéia: a de utilizar representantes de venda para este empreendimento. Isso lhe permitiria dividir com os representantes as tarefas de interação com os clientes e não sobrecarregaria a sua folha de pagamento tendo que fazer novas contratações. Um novo diagrama de fluxo e estoque foi então elaborado, conforme Figura 3.

Com a introdução de representantes de vendas pode-se esperar que inicialmente haja uma queda na qualidade do serviço devido a dois fatores: os recursos da empresa deverão ser destinados em parte para a formação dos representantes de venda, diminuindo os investimentos no website; o tempo que o proprietário terá que deixar de atender os clientes para se dedicar à formação dos representantes de vendas. Essa queda na qualidade do serviço não deve ser considerada como uma tomada de decisão incorreta, mas sim como um atraso que o sistema possui para reagir. No médio prazo a tendência será de melhora no atendimento.

A sugestão é que a empresa Alfa forme essa equipe de representantes de venda e só então lance o e-commerce. Desta forma estará apta a prestar um bom atendimento aos clientes. 


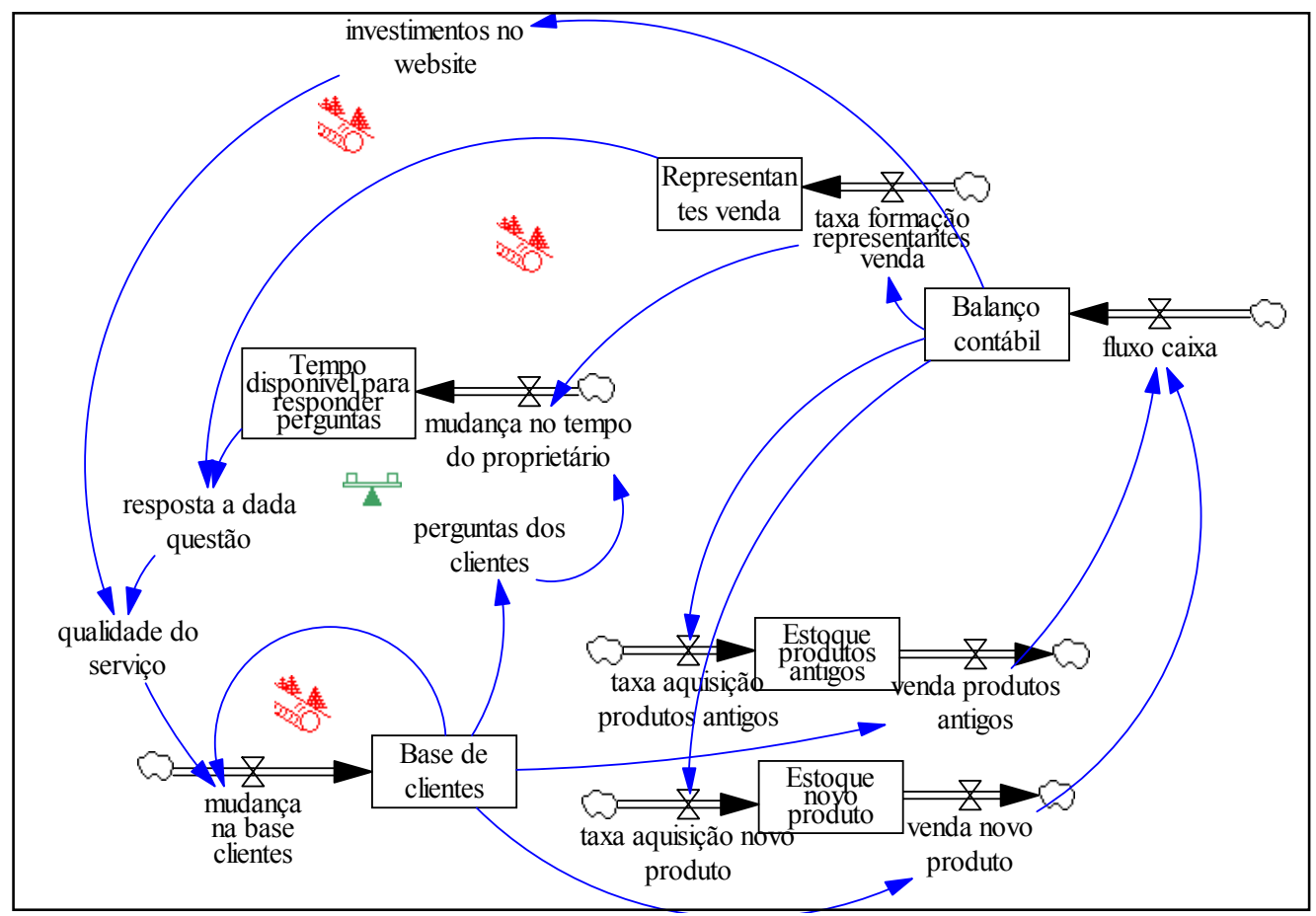

Figura 3 - Diagrama de fluxo e estoque introduzindo os representantes de vendas

\section{Referências}

BIANCHI, C. (2002) - Editorial. System Dynamics Review Autumn 18, 3, pp.311-314.

BIANCHI, C. (2003) - Introducing SD modelling into planning and control systems to manage SME's growth: a learning-oriented perspective. System Dynamics Review Autumn 18,3, pp.315-338.

BIANCHI, C. \& BIVONA, E. (2002) - Opportunities and pitfalls related to e-commerce strategies in smallmedium firms: a system dynamics approach. System Dynamics Review Autumn 18,3, pp. 403-429.

CHAPPELL, C. \& FEINDT, S. (1999) - Analysis of E-commerce practice in SMEs. Disponível em: <http:// kite.tsa.de>. Acesso em: 6 abr.2005.

CHAPPELL, C.; FEINDT, S. \& JEFFCOAT, J. (1999) - Gazelles and Gophers: SME Recommendations for Successful Internet Business. Disponível em: <http:// kite.tsa.de>. Acesso em: 6 abr.2005.

DREW, S. (2003) - Strategic Uses of E-Commerce by SMEs in the East of England. European Management Journal Vol.21, No.1, pp.79-88.

OLIVA, R.; STERMAN, J.D. \& GIESE, M. (2003). Limits to growth inthe new economy: exploring the "get big fast" strategy in e-commerce. System Dynamics Review 19, 2, pp. 83-117.

PORTER, M. (2001) - Strategy and the Internet. Harvard Business Review March, pp. 63-78.

ROCKART, J.F.(1979) - Chief executives define their own data needs. Harvard Business Review March/April, pp.81-92.

SOUITARIS, V. \& COHEN, M. (2003) - Internet-Business or Just Business? Impact of “Internet-Specific" Strategies on Venture Performane. European Management Journal Vol.21, No.4, pp.421-437.

STERMAN, J. D. (2000). Business Dynamics: Systems Thinking and Modeling for a Complex World. Mc Graw Hill. Boston.

STERMAN, J. D. (2001). System Dynamics Modeling: Tools for Learning in a Complex World. California Management Review Vol.43, No.4.

WALCZUCH, R.; BRAVEN, G.V. \& LUNDGREN, H. (2000) - Internet Adoption Barriers for Small Firms in The Netherlands. European Management Journal Vol.18, No.5, pp.561-572. 